\title{
GESTÃO DE PROJETOS DE INOVAÇÃO: O CASO DE UMA EMPRESA LÍDER DO SETOR DE ELETRODOMÉSTICOS
}

\author{
Celso Machado Junior \\ Doutor em Administração pela Universidade Nove de Julho - UNINOVE \\ Professor do Programa de Pós-graduação em Administração no Centro Universitário das Faculdades \\ Metropolitanas Unidas - FMU \\ celsomachado1@gmail.com (Brasil)
}

\section{Leonel Mazzali}

Doutor em Economia de Empresas pela Fundação Getulio Vargas - FGV

Professor do Centro Universitário das Faculdades Metropolitanas Unidas - FMU

leonel_mazzali@uol.com.br(Brasil)

\section{Angelo Palmisano}

Doutor em Ciências Sociais pela Pontifícia Universidade Católica de São Paulo - PUC/SP

Pró-Reitor Pós-Graduação, Pesquisa e Extensão do Centro Universitário das Faculdades Metropolitanas Unidas - FMU

angelo.palmisano@fmu.br (Brasil)

\section{RESUMO}

O estudo objetiva identificar configurações de gestão de projetos de inovação utilizadas nas organizações. Desenvolveu-se uma pesquisa qualitativa recorrendo a técnica do estudo de caso. O estudo de caso realizado abarca uma empresa líder no ramo de eletrodomésticos, situada entre as dez empresas que mais registram patentes no Brasil. Os dados observados mostram que a empresa possui um processo definido e sistematizado de acompanhamento de produtos novos, com protocolos muito bem definidos para suportar as atividades requeridas, visando disciplinar a análise de benefícios e riscos envolvidos na execução, e estabelecer regras e comportamentos para projetos que possuam similaridades. Ademais, a empresa incrementa o alinhamento com o ambiente externo, possibilitando a integração das diferentes áreas técnicas, para atender à complexidade tecnológica. Os resultados indicam que a empresa adota um modelo de gestão de inovação apoiado em uma Equipe de Projetos configurada a partir de uma estrutura matricial, com um Piloto de Projetos. O Piloto do Projetos se posiciona como agente central do processo, por atuar como agente integrador da multidisciplinaridade e realizar a ponte da equipe com a alta administração. A configuração do processo de gestão se apresenta dividida em etapas distintas com atribuições especificas que demandam procedimentos de controle, consubstanciados em "protocolos de encerramento". A aprovação do projeto é realizada pela alta administração em cada uma das fases, em reuniões especificas que analisam, os custos, o atendimento dos prazos e o desenvolvimento tecnológico das inovações em curso.

Palavras-chave: Escritório de projetos; Gestão de projetos; Equipe de projetos; Piloto de projetos. 


\section{INTRODUÇÃO}

A importância da inovação para o desenvolvimento da economia se revela a partir das proposições de Schumpeter (1939, 1982). Para este autor, as inovações não são importantes apenas para o ambiente competitivo das organizações, mas também para o desenvolvimento das próprias nações. Nesta abordagem, o processo de inovação incorpora contornos que influenciam a sociedade como um todo, não se limitando somente aos arranjos sociais que constituem as organizações. $\mathrm{O}$ manual de Oslo (OCDE, 2005), publicado inicialmente em 1992, estabelece um ambiente favorável à criação de indicadores que possibilitam a comparação do tema inovação entre os países.

A inovação parte de proposição de algo ainda não existente, que pode atender necessidades reais ou potenciais da sociedade. Uma boa ideia possui desta forma o desafio de se tornar um produto ou serviço de qualidade, no menor espaço de tempo possível e a custos interpretados como adequados pelos futuros clientes. Destaca-se assim, a importância do processo que envolve o período entre a determinação de desenvolver uma ideia inovadora e a entrega de um produto ou serviço inovador.

Independente do porte, as organizações necessitam realizar a gestão de todas as fases do projeto de inovação para a manutenção dos prazos e custos planejados. Quanto maior o grau de complexidade, em decorrência do número de atividade executadas, maior a necessidade do controle sobre prazos e custos. As organizações podem adquirir inovações (patentes), desenvolvimento tecnológico, máquinas, ferramentas, entre outros itens, no entanto não podem abdicar da gestão compartilhada dos projetos de inovação, fator determinante da sua viabilidade.

Estudos efetuados por Chaos Report (1995), Marques Junior (2000) e Shenhar e Dvir (2007) apresentam o desempenho obtido no desenvolvimento de projetos e indicam o grau de dificuldade no atendimento das metas propostas. As conclusões são as seguintes: apenas $28 \%$ dos projetos de tecnologia de informação obtêm êxito frente às metas iniciais propostas, observando-se atraso médio de $103 \%$ nos projetos de construção e reforma e apenas um em cada quatro produtos desenvolvidos alcança êxito comercial. Estudos levados a efeitos por Joshi e Sharma (2004) estimam que 46\% dos recursos empregados pelas empresas na concepção, no desenvolvimento e no lançamento de novos produtos são mal alocados. Estes resultados expressam a dificuldade dos gestores de projetos em atender as metas de desempenho estabelecidas para monitorar os projetos.

As organizações necessitam estabelecer estruturas organizacionais adequadas para atender a demanda de gerenciamento dos processos de inovação. Conforme apontam Rabechini Junior et al. (2011), nem sempre a estrutura organizacional é adequada para o gerenciamento dos projetos que envolvem o desenvolvimento das inovações. Vale destacar que as estruturas organizacionais variam 
em função de sua cultura interna e do ramo de atividade, o que inviabiliza a existência de uma estrutura padrão. No entanto, é possível identificar a expectativa de um padrão de gestão que favoreça o envolvimento das pessoas no desenvolvimento das inovações, não se atendo somente ao atendimento das atividades de rotina. Nesse sentido, vale destacar a pesquisa de De Negri e Salerno (2005), revelando que as empresas brasileiras que inovam geram postos de trabalho de maior qualidade, que demandam mão-de-obra mais qualificada, mais bem remunerada e com maior estabilidade no emprego.

Segundo Sbragia e Lima (2013), quanto maior for a orientação das organizações para o mercado, maior será a integração e a confiança entre as áreas funcionais envolvidas para o desenvolvimento de novos produtos. Este contexto estabelece a importância dos participantes do grupo de projetos e da coesão do grupo de desenvolvimento dos projetos, em associação com a orientação para o mercado. Este resultado indica que o grupo de projetos deve estar alinhado com o ambiente externo das organizações, e não circunscrito apenas às atividades relacionadas ao projeto.

A importância da gestão dos processos voltados às inovações nas organizações fica evidente face às particularidades originadas da estrutura organizacional e das pessoas que executam essa atividade. Nesse âmbito, a questão que se coloca é: De que forma se estrutura o processo de desenvolvimento e de implantação de inovações nas organizações?

O presente estudo objetiva identificar configurações da gestão de projetos de inovação utilizadas em uma empresa inovadora, mais precisamente, uma empresa líder do setor de eletroeletrônicos, que se posiciona entre as dez empresas que mais registram patentes no Brasil.

Este trabalho está organizado da seguinte forma: a primeira parte é a introdução, onde consta o objetivo a ser alcançado. A segunda parte contempla a orientação teórica adotada pela pesquisa. A terceira parte é composta pela metodologia, onde constam todos os procedimentos utilizados para o alcance do objetivo proposto. A quarta parte apresenta o estudo de caso desenvolvido. A quinta e última parte contempla as conclusões, as limitações e as sugestões para a realização de futuras pesquisas sobre os temas em questão.

\section{O GERENCIAMENTO DE PROJETOS DE INOVAÇÃO}

O desenvolvimento de projetos apresenta tanto desafios como oportunidades para as organizações. Em pesquisa desenvolvida por Kessler, Bierly e Gopalakrishnan (2000), envolvendo empresas de grande porte dos EUA, de variados setores da economia, observou-se que o conhecimento

Revista de Administração e Inovação, São Paulo, v. 12, n.3 p. 288-309, jul./set. 2015. 
gerado internamente à firma representa maiores benefícios do que aqueles obtidos de fontes externas. Segundo os autores, no desenvolvimento interno do projeto ocorre o compartilhamento de conhecimentos na geração de ideias, potencializando maior comprometimento e engajamento da equipe de trabalho.

O gerenciamento de projetos nas organizações está circunscrito no rol de atenção dos executivos. Autores como Ibbs e Kwak, (2000) e Raz, Shenhar e Dvir (2002) pesquisaram o gerenciamento de projetos e as suas implicações na obtenção das metas propostas, que, no geral, envolvem variáveis como prazo e custos.

Para Rabechini Junior et al. (2011), as empresas buscam estruturas funcionais com baixo nível de formalização para articular as atividades rotineiras e as não rotineiras. Nesse sentido, as estruturas se apresentam com multiplicidade de comando, compostas de elevada diversificação nas estruturas organizacionais e com bom processo de comunicação horizontal e diagonal.

Segundo Patah e Carvalho (2002), a estrutura funcional apresenta limitações para o bom desenvolvimento de projetos que envolvam inovações. A necessidade intrínseca de diversificar e integrar tecnologias no desenvolvimento dos processos e produtos atua como estimulo à busca de novos arranjos organizacionais, pautados em uma maior integração, principalmente na busca de soluções para os problemas que se apresentarem. Para os autores, uma estrutura matricial ou híbrida, que concilie a estrutura funcional com a estrutura de projetos é a que melhor possibilita a integração das diferentes áreas técnicas, necessária para atender à complexidade tecnológica contemporânea. Os autores destacam, na estrutura matricial, a importância do papel do gerente de projetos, e a sua autoridade sobre o projeto como um todo, confirmando assim posições de autores como Meredith e Mantel Junior (2000) e Kerzner (2001).

A estrutura matricial proporciona uma melhor distribuição de atividades pertinentes ao projeto pelos diversos setores da organização. Essa distribuição possibilita a racionalização dos recursos envolvidos, além do compartilhamento da autoridade e da responsabilidade entre o gerente funcional e o gerente do projeto. No entanto, por se caracterizar como uma estrutura de duplo comando é provável a emergência de conflitos entre os membros da equipe. Assim, um gerente de projetos, atuando em uma estrutura matricial, necessita possuir perfil de líder e de bom negociador, a fim de evitar competições desgastantes pelos recursos técnicos disponíveis na empresa (Meredith; Mantel Junior, 2000; Kerzner, 2001).

Segundo Williams (2005), os documentos de orientação de boas práticas denominados como Bodies of Knowledge-Books em gestão de projetos, da década de 1990, renovaram o foco no planejamento e controle dos projetos, solidificando, assim, a visão normativa e prescritiva da gestão de 
projetos. Nesse contexto, emerge o entendimento de que basta seguir as melhores práticas que os projetos obterão êxito.

Os escritórios de projetos se estabelecem como uma "célula contida na estrutura organizacional", com a finalidade especifica de administrar todas as etapas envolvidas no desenvolvimento do novo produto. Adicionalmente, realizam a interface entre o gerente de projetos e a alta administração, por meio de um sistema de feedback (Bernstein, 2000; Kendall; Rollins, 2003).

Segundo Rodrigues, Rabechini Júnior e Csillag (2006) é possível observar que os escritórios de projeto se apresentam em diversas concepções e funções, de acordo com o estágio de evolução da área na empresa e do tipo de estrutura organizacional predominante, dentre outros fatores. Nesse universo, há escritórios destinados unicamente a reportar o desempenho dos projetos aos responsáveis pelas estratégias e se responsabilizam pela equipe de projetos.

Para Shenhar e Dvir (2007), a abordagem tradicional ou convencional de gestão de projetos se materializa nos seguintes passos: início do processo com a criação de uma declaração de escopo, que define o que precisa ser feito e aponta os principais produtos/serviços a serem entregues. Na sequência, o escopo é dividido em pacotes de trabalho, hierarquicamente organizados em uma Estrutura Analítica de Projeto - EAP. A EAP fundamenta a estrutura organizacional do projeto. Após esta etapa, monta-se a rede de atividades do projeto, com a alocação dos recursos necessários, associada ao cronograma do projeto. Outros elementos do plano do projeto são então agregados. O controle do projeto se destina a garantir a sua realização dentro do prazo, do orçamento e das especificações. Para os autores, a adoção de um modelo de gestão de projetos se destina a disciplinar a análise de benefícios e riscos envolvidos na execução, bem como estabelecer regras e comportamentos para projetos que possuam similaridades.

Para Diegel (2002), a realização de atividades de forma organizada, objetivando a implantação de um produto/serviço desde a sua concepção até a comercialização, configura um projeto, por tratarse de um empreendimento composto por etapas definidas, com começo, meio e fim.

Neste contexto, o modelo Stage Gate ${ }^{\mathrm{TM}}$ propõe uma sequência de fases do projeto de desenvolvimento de novos produtos, isto é, uma série de estágios finalizados, na grande maioria dos casos, por pontos de revisão das fases (gates). Os estágios classificados por Cooper (1995) são tipificados nas etapas do projeto. Os pontos situados entre os estágios destinam-se ao feedback do que foi feito, analisando o desempenho do projeto e autorizando o início da etapa seguinte. A Figura 1 apresenta o modelo Stage Gate ${ }^{\mathrm{TM}}$. 


\section{Figura 1}

Processo de Desenvolvimento de Novos Produtos.

$\begin{array}{ccccc}\text { Pesquisa } & \text { Pesquisa } & \text { Desenvol- } & \text { Teste e } & \text { Produção e } \\ \text { Inicial } & \text { Detalhada } & \text { vimento } & \text { Validação } & \begin{array}{c}\text { Lançamto } \\ \text { no Mercado }\end{array}\end{array}$

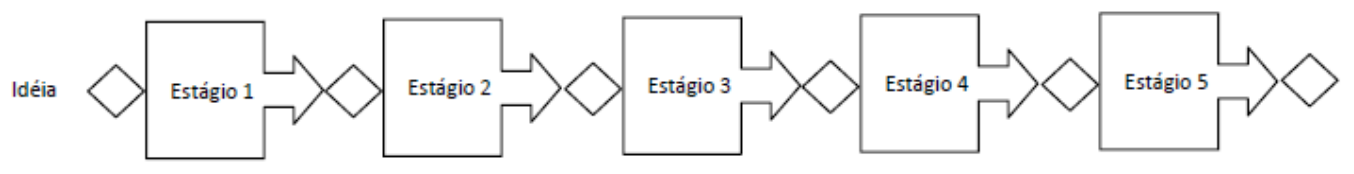

$\begin{array}{cccccc}\text { Panorama } & \text { Panorama } & \text { Decisão } & \text { Revisão Pós- } & \text { Análise do } & \text { Revisão Pós- } \\ \text { Inicial } & \text { Secundário } & \text { pela } & \text { Desenvolvimento } & \text { Negócio } & \text { Implantação } \\ & & \text { pesquisa } & & & \end{array}$

Fonte: Adaptado de Cooper (1995).

O modelo Stage Gate ${ }^{\mathrm{TM}}$ possui um mecanismo de conexão do desenvolvimento de novas tecnologias com as vendas, o mercado e o consumidor (Bremser; Barsky, 2004). Isso condiciona a existência de constantes feedbacks, principalmente a cada nova fase do projeto. Tal conduta possibilita maior interação entre as áreas responsáveis pela concepção do novo produto, ou serviço. O modelo Stage Gate ${ }^{\mathrm{TM}}$, apresentado por Cooper (1995), indica que os projetos de desenvolvimento de novos produtos se compõem de etapas integradas, com a participação de diversas áreas da empresa.

$\mathrm{O}$ modelo Stage Gate ${ }^{\mathrm{TM}}$ apresenta um processo único que incorpora todas as fases de gestão do projeto. Outros modelos foram desenvolvidos com o objetivo de detalhar as etapas de desenvolvimento tecnológico e a de desenvolvimento de produto. Dentre estes modelos destaca-se o proposto por Caetano, Kurumoto e Amaral (2012) apresentado na Figura 2.

\section{Figura 2}

Modelo de gestão de produto integrando processo de desenvolvimento de tecnologia e o processo de desenvolvimento de produto.

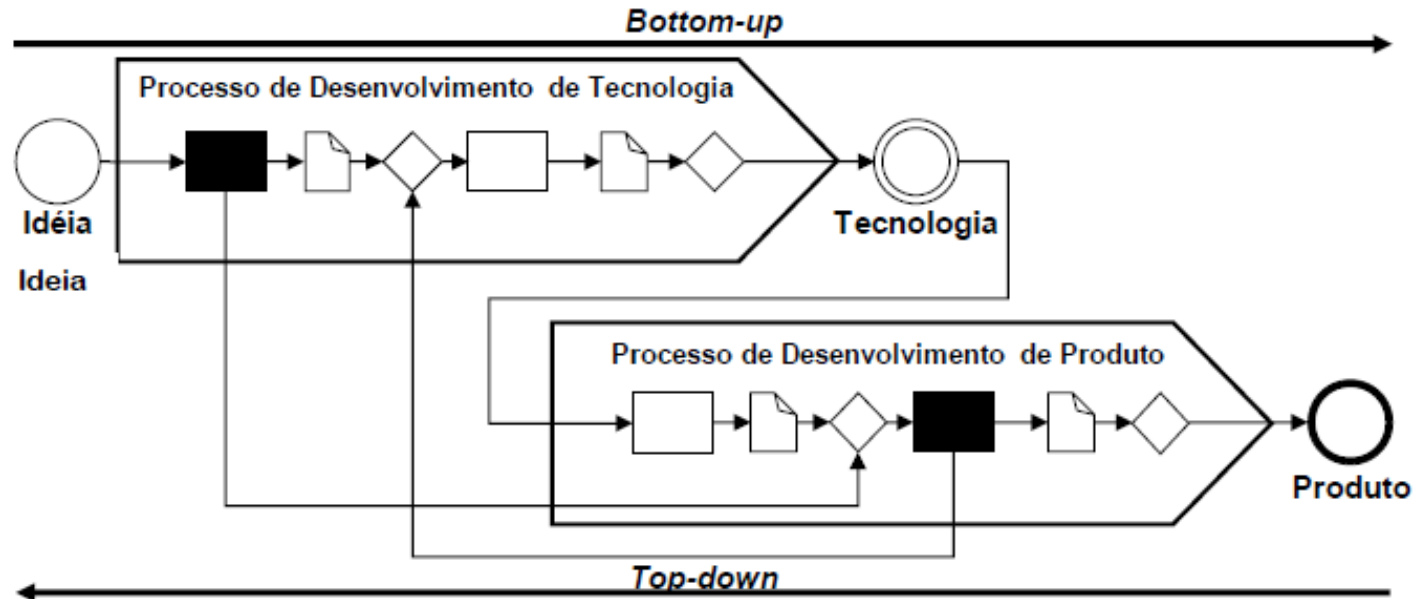

Fonte: Caetano, Kurumoto e Amaral (2012) 
O modelo proposto por Caetano, Kurumoto e Amaral (2012) divide o processo principal em dois processos distintos. No primeiro, se realiza o desenvolvimento tecnológico da inovação, e somente após encontrar a solução tecnológica é que se inicia efetivamente o desenvolvimento do produto. Os autores destacam a importância da integração entre os dois processos, e para tanto indicam, no modelo, as atividades criticas (representadas na figura de forma preenchida). O modelo mostra a necessidade de feedback entre estes processos. Vale destacar que o modelo não informa ser uma única equipe de projeto ou se há equipes distintas para cada um dos processos, no entanto, é de se esperar que esta distinção ou não de equipes de projeto seja uma particularidade de cada projeto e de cada organização.

Outro aspecto a se ponderar no modelo proposto é que há tanto um fluxo de informações bottom-up, ou seja, da equipe de projetos para a direção da organização, quanto top-down, ou seja, da direção da organização para a equipe de projetos. Esses fluxos bidirecionais de informações indicam um monitoramento da organização sob a equipe de trabalho. Monitoramento que deve pautar, entre outros tópicos, os custos e os prazos envolvidos.

O gerenciamento de projetos de inovação configura-se, então, como um processo a ser executado por uma equipe multidisciplinar especifica, atuando de forma matricial e com um gestor (Piloto de Projeto) especifico. A figura do Piloto de Projeto é de fundamental importância, porque, além de coordenar a equipe, é responsável por municiar a alta administração com as informações relevantes do projeto, bem como compilar todo o conhecimento e documentos envolvidos. Fica patente, também, que o Piloto e a Equipe de Projeto de Inovação devem seguir um roteiro fixo de atividades que se divide em etapas. As etapas possuem atividades específicas, que para se encerrarem necessitam da aprovação da alta administração. É no encerramento dessas etapas que a alta administração analisa o desempenho do projeto e define a sua continuidade ou não. Nesse sentido, o papel da alta administração é fundamental no processo de inovação, definindo a continuidade do projeto, por meio da aprovação dos recursos necessários para a etapa seguinte e análise de adequação dos custos, dos prazos e dos critérios técnicos. Na sequência, apresentam-se os procedimentos metodológicos envolvidos nesta pesquisa. 


\section{PROCEDIMENTOS METODOLÓGICOS}

Frente ao objetivo proposto pela pesquisa, identificou-se a adequação de empreender uma pesquisa qualitativa exploratória. Esta opção se apoia na proposição de Gil (2010), que aponta a harmonização do estudo exploratório com a familiarização do fenômeno pelo pesquisador, com a ampliação do conhecimento ou o alcance de uma nova percepção. É um tipo de pesquisa flexível e versátil e não estruturada, que não visa à confirmação de hipóteses, mas a descoberta de novas ideias.

A estratégia de pesquisa é o estudo de caso. Esta opção de investigação se apoia na proposição de Yin (2010), que classifica o estudo de caso como a busca do entendimento da dinâmica em um contexto singular de fenômenos, sejam eles, individuais, grupais, organizacionais, sociais, políticos e afins. O caso em questão se refere a uma empresa líder no ramo de eletrodomésticos, com sede na França e atuação global. Foi objeto de estudo a sua unidade sediada no Brasil.

A principal técnica de coleta de dados utilizada foi a análise documental. Os pesquisadores tiveram acesso a manuais e a procedimentos envolvidos no processo de desenvolvimento de produtos novos. A empresa disponibilizou dois tipos de documentos: os referentes aos procedimentos adotados e os referentes aos resultados obtidos. A documentação dos procedimentos adotados aborda a metodologia empregada pela empresa e a sua respectiva atualização ao longo do tempo. A documentação dos resultados obtidos com os produtos foi parcial e restrita a apenas alguns itens mais antigos. A opção da empresa é justificada pelo desejo de não divulgar informações que possam impactar em suas estratégias mercadológicas. No entanto, a restrição estabelecida não se apresentou como limitação à obtenção do objetivo proposto por esta pesquisa. Adicionalmente, as dúvidas levantadas durante a investigação documental pelos pesquisadores foram sanadas pelo responsável em desenvolvimento de produtos novos.

A análise documental obedeceu às seguintes etapas: organização do material, leitura preliminar, identificação dos pontos relevantes, categorização das atividades frente ao referencial teórico e redação do texto.

O núcleo do protocolo para a coleta de dados nos estudos de caso é [...] "um conjunto de questões substantivas que refletem sua verdadeira linha de investigação" (Yin, 2010, p. 112). Nesse sentido a investigação foi dividida em três temas e conduzida para alcançar o entendimento dos seguintes pontos

Em primeiro lugar, no que se refere à gestão: a) Quem participa do projeto e quais os critérios utilizados para a definição da participação? b) Quem coordena os integrantes do projeto e quais são suas atribuições? c) Como ocorre o processo de coordenação entre as diferentes áreas? d) Qual a 
participação da alta administração e em que momentos ela ocorre? e) Quais os mecanismos utilizados para o monitoramento e a implantação dos projetos? f) Quais os indicadores utilizados para avaliar os projetos?

A segunda abordagem busca identificar a sequência de atividades atreladas ao desenvolvimento dos projetos: a) São claramente definidas fases e o que as caracteriza? b) Quais os critérios para definir a passagem de uma fase do projeto à seguinte? c) Qual a participação da alta administração em cada uma das fases?

E, finalmente, a pesquisa se volta à questão da reavaliação do projeto de inovação: a) Como ocorre a reavaliação do processo de inovação? b) Qual a frequência? c) Quais os procedimentos? Vale destacar, que este conjunto de indagações tem a intenção de auxiliar o processo de investigação para o atendimento do objetivo proposto.

A empresa objeto de estudo solicitou a sua não identificação, demanda esta atendida pelos pesquisadores. No entanto, o estudo de caso apresenta as principais características da empresa, possibilitando ao leitor a contextualização e a significância da pesquisa desenvolvida.

\section{ESTUDO DE CASO E DISCUSSÃO}

Nesta seção é apresentada a empresa objeto de estudo deste artigo e os dados obtidos na investigação realizada na documentação que envolve o processo de desenvolvimento de novos produtos.

\subsection{A empresa - EletrodomésticosA}

A origem da EletrodomésticosA data do ano de 1940. Fundada por um imigrante italiano, voltou-se inicialmente à fabricação de motores elétricos. A partir de 1947 a empresa diversificou suas atividades, incorporando a produção de peças automotivas, e na sequência, os primeiros eletrodomésticos do país. Em 1997, com suas atividades direcionadas exclusivamente para a produção de eletrodomésticos foi adquirida por um grupo francês. Esse grupo é líder mundial na fabricação de eletro portáteis, presente em mais de 120 países, com um portfólio de 14 marcas (cinco internacionais e nove regionais) e um quadro de aproximadamente 18.000 funcionários. O grupo possui uma política de inovação em âmbito mundial, na qual cerca de $2 \%$ do seu faturamento global é destinado à pesquisa e à inovação tecnológica.

Revista de Administração e Inovação, São Paulo, v. 12, n.3 p. 288-309, jul./set. 2015. 
A aquisição da EletrodomésticosA além de expandir sua atuação no segmento original em âmbito nacional, possibilitou o incremento de suas exportações. As exportações, antes restritas a países da América do Sul, foram ampliadas para outras localidades em que o grupo mantinha atividades comerciais, principalmente na Europa.

Após o processo de incorporação pelo grupo multinacional, a EletrodomésticosA manteve as atividades e os departamentos voltados à inovação e ao desenvolvimento tecnológico, os quais passaram por uma integração com a estrutura global de pesquisa e desenvolvimento tecnológico. A análise documental possibilitou identificar que, no ano de 2003, foi introduzida uma nova sistemática de gestão de projetos de inovação. O novo modelo de gestão de projetos inclui a EletrodomésticosA no interior da metodologia utilizada pelo grupo francês.

Os dados a seguir foram obtidos de documentos da EletrodomésticosA e se apoiam em material revisado no ano de 2007. O modelo de gestão apresenta-se expresso em documento da companhia e disponível via computador para todos os funcionários da organização e expressa o seguinte objetivo:

O objetivo principal desse processo é de respeitar os compromissos assumidos em termos de Qualidade, Custos e Prazos dos lançamentos dos novos produtos (EletromésticosA, 2007).

Visão geral da gestão do processo de inovação: atividades ligadas à pesquisa e atividades ligadas ao desenvolvimento de produtos

O processo de pesquisa e desenvolvimento dos produtos da EletrodomésticosA decompõe-se em 2 grandes blocos de atividades, suficientemente detalhados na Figura 3. Cada um dos blocos é gerido por um comitê especifico.

O primeiro é a Pesquisa que comporta duas fases (busca e validação de soluções), ficando sob a responsabilidade do Comitê de Inovação. Como se percebe, o Comitê de Inovação atua no levantamento e na análise de viabilidade de inovações. Nesta fase, o projeto é tratado de forma confidencial, ficando restrito a poucos participantes (a EletrodomésticosA não divulgou a estrutura deste comitê, no entanto foi possível observar a existência de uma estrutura física especifica para o desenvolvimento desta fase).

As Fases 0 e 1 pertencem ao estágio de pesquisa e incorporam as inovações pretendidas para os produtos. Estas fases se apoiam nas necessidades do consumidor, na análise da concorrência e nas tendências sociológicas (Prospecção) - nas oportunidades tecnológicas, na estratégia de empresa, na “observação sistemática" de fonte de suprimentos, no balanço da Pesquisa dos anos anteriores, entre outros fatores. A descrição sintetizada das duas fases que integram a gestão da pesquisa é a seguinte:

Revista de Administração e Inovação, São Paulo, v. 12, n.3 p. 288-309, jul./set. 2015. 
Fase 0 - Busca de soluções (uma função, um subconjunto, um novo conceito, uma nova tecnologia). Os caminhos de pesquisa identificados são filtrados e listados num Plano de Pesquisa validado por um Comitê de Inovação. Uma primeira fase de pesquisa de soluções potenciais é iniciada e pilotada pelo responsável do departamento de Pesquisa. O trabalho se conclui pela escolha claramente argumentada de uma ou mais soluções técnico-econômicas, formalizadas no primeiro resumo de projeto $(\mathrm{RP} 0)$.

Fase 1 - Validação das soluções: as soluções escolhidas na fase anterior são prototipadas e sofrem pré-validações técnicas (viabilidade construtiva de fabricação, análise das orientações de design e validação da função/conceito), econômicas e mercadológicas. Essa fase é concluída por um balanço de pesquisa e, preferencialmente, por uma decisão de lançamento de um projeto de desenvolvimento de um produto (ou uma família de produtos), integrando a função ou o subconjunto pré-validado. A aprovação é documentada no resumo de projeto (RP1).

\section{Figura 3}

Processo de pesquisa e desenvolvimento dos produtos da EletrodomésticosA
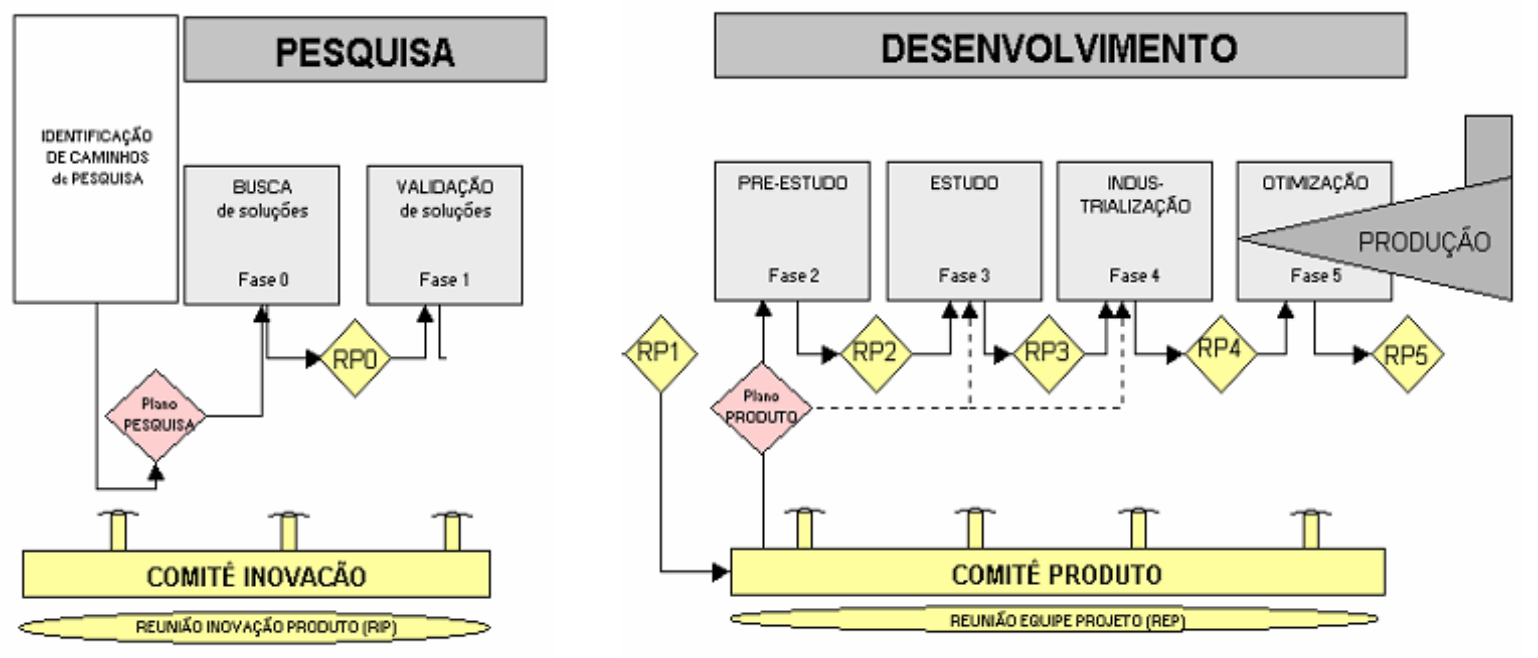

Fonte: dados fornecidos pela EletrodomésticosA.

O segundo bloco de atividades é o Desenvolvimento composto de quatro fases: Pré-estudo; Estudo; Industrialização e Otimização . É nesta etapa do projeto que atua a equipe de projetos também denominada de Comitê de Produto.

Cada uma das fases possui um conjunto característico de atividades a serem executadas. Estas fases estão descritas na sequência.

Após a conclusão da Fase 1, a Diretoria da EletrodomésticosA designa o Piloto e a equipe de Projeto que gerenciarão o desenvolvimento do novo produto. Neste momento também são definidas as metas relacionadas a prazo, custo e desempenho do produto. Vale destacar que, antes de oficialmente 
se iniciar o desenvolvimento do produto, o projeto é encaminhado para o Vice Presidente Executivo do Grupo (Estratégia e Unidades de Negócios - Industrial) que analisará os dados e, ao final, deve expressar a sua concordância ou não, com o projeto. Esta ação deve ser executada em um prazo de 15 dias úteis.

Fase 2 - Pré-estudo: esta fase é caracterizada pela conciliação da viabilidade técnica do produto e fabricação através de análises críticas em relação ao design. O piloto do projeto coordena o conjunto de atividades da equipe do projeto. A equipe tem como objetivo cumprir/otimizar/precisar o compromisso assumido no fechamento do resumo do projeto - RP1 (design/preço/prazo/investimento/volume). Essa fase é validada por testes com consumidores, estudo de rentabilidade e teste de desempenho. Com todos os dados de entrada do produto e o dossiê de rentabilidade atualizado, a Direção Geral do Grupo deve opinar sobre a continuação ou não do projeto em um prazo de 15 dias úteis. O conjunto é revisado e aceito no resumo do projeto (RP2).

Fase 3 - Estudo: A partir dos dados de entrada atualizados e aceitos pela equipe de projeto quando da confecção do resumo do projeto - RP2, os membros do projeto definem o produto até o último detalhe, incluindo todos seus componentes e os recursos industriais e humanos necessários para sua produção. Esse estudo é validado com testes de desempenho no protótipo funcional, validação junto aos consumidores e análises de risco, incluindo um dossiê atualizado de rentabilidade. Essa fase é concluída pela decisão de lançamento do investimento industrial (resumo do projeto - RP3).

Fase 4 - Industrialização: essa fase consiste principalmente em executar ou mandar executar as ferramentas e os equipamentos de produção, assim como definir mecanismos de controle e ajustes. Faz parte dessa fase a efetivação de, no mínimo, 2 (dois) try-outs para os componentes e peças fabricadas e a realização do lote piloto de, ao menos, 2000 unidades. Destaca-se que a homologação (aprovação para produção e vendas) somente ocorre após a realização do try-out e do lote piloto. Finalmente, a implantação do plano de lançamento comercial. Essa fase é concluída pela decisão de comercialização do produto e pela definição de um plano de eventuais ações corretivas que serão realizadas na Fase 5. É necessário um tempo mínimo entre o início de produção e o início das vendas (de 15 a 30 dias). Esse tempo é importante para verificar o processo produtivo antes das vendas. A conclusão desta fase se encerra com a autorização de produção e comercialização do produto (resumo do projeto - RP4).

Fase 5 - Otimização: esta fase inicia-se com a administração da Lista Única de Problemas (LUP) gerada quando da formalização do RP4. Porém, também são administrados outros assuntos que surgem no decorrer da produção, como, por exemplo, não alcançar o ritmo de produção esperado, altas taxas de retrabalho e/ou de sucata e baixos níveis de qualidade. O piloto e a equipe de projetos implantam planos de ações até sua conclusão final. Essa fase é concluída por um balanço do projeto 
pondo um ponto final ao projeto, oficializado durante a confecção do resumo do projeto - RP5. Qualquer nova ação de modificação do produto (modificação de gama, redução de custo, etc.) será considerada outro projeto e possuirá outro sistema de gerenciamento mais adequado a esta finalidade.

Estrutura de gestão dos processos: equipes multidisciplinares (de projetos)

Para o atendimento das atividades envolvidas no processo de desenvolvimento e industrialização, os projetos da EletrodomésticosA são suportados por equipes multidisciplinares (equipes de projeto), com a coordenação de um Piloto de Projeto. A Figura 4 apresenta a configuração das equipes de projetos.

\section{Figura 4}

Equipe de projeto

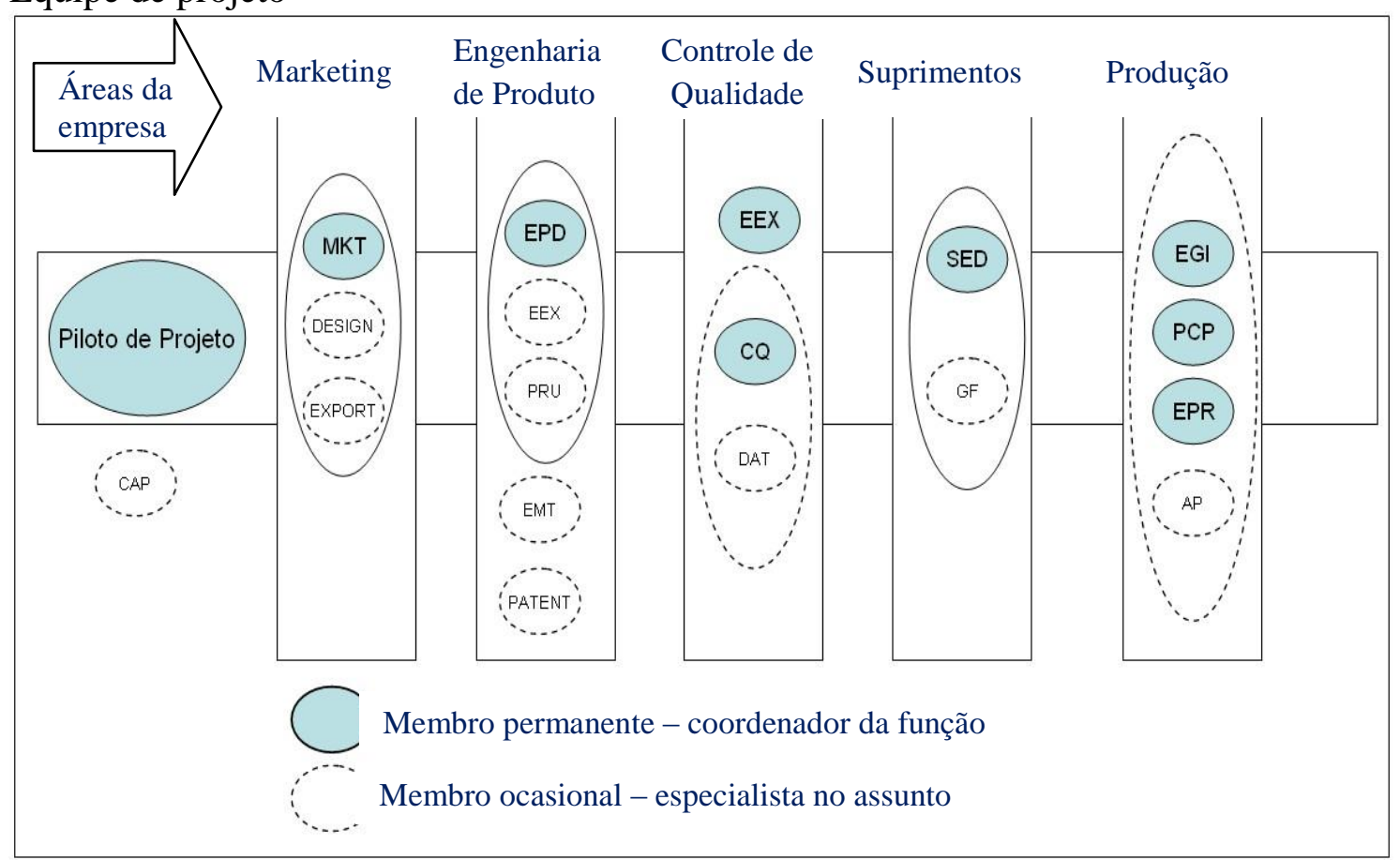

Notas. CAP = Centro de Apoio a Pesquisa; DESIGN = responsável pelo design do produto; EXPORT = representante do setor de exportação; EPD = representante do setor de Projeto de produtos; EEX = representante do setor de Ensaios Técnicos; PRU = representante do departamento de custos; EMT = representante do setor de Engenharia de Materiais; PATENT = representante do setor de registro de marcas e patentes; $\mathrm{CQ}=$ representante do setor de Controle de Qualidade; DAT = representante do setor de Assistência Técnica; SED = representante do setor de suprimentos; GF = representante do departamento de gestão de fornecedores; EGI = representante da engenharia industrial; PCP = representante pelo Planejamento e Controle da Produção; EPR = representante pela engenharia de processos de fabricação; AP = representante da Linha de Montagem do produto. Fonte: dados fornecidos pela EletrodomésticosA.

A equipe de projeto é composta por membros fixos e membros com participação ocasional, mediante a convocação para atendimento a demandas especificas e pontuais. 
O Piloto de Projeto se posiciona como o responsável pela coordenação da equipe e com espectro de atuação junto a todos os demais participantes. Observa-se ainda que todas as áreas funcionais envolvidas possuem, no mínimo, um representante. Esta configuração possibilita que o representante de área realize a interface da equipe com as respectivas áreas de atuação, garantindo a sinergia do desenvolvimento do produto com as demais áreas da organização. Abaixo as responsabilidades apontadas aos membros da equipe de projetos:

A equipe de projeto trabalha implantando as competências diversas dos seus membros (conhecimentos e "know-how") para atingir os objetivos que se definiu para levar o projeto para frente.

O piloto de projeto coordena a equipe de projetos é responsável, junto com a mesma, pelo atendimento dos compromissos em termos de prazos, custos, qualidade.

Membro de projeto é o representante da sua área de atuação dentro da equipe de projeto (coordenação dos trabalhos relativos e informação dos gestores).

O gerente de departamento garante, entre outras coisas, o bom desempenho dos seus colaboradores dentro dos projetos. Garante que as soluções propostas pelos atores da sua função estejam em adequação com os objetivos do projeto (ELETRODOMÉSTICOS A, 2007).

\subsection{Mecanismos de controle}

Como se viu anteriormente, a conclusão de cada fase é consolidada por um documento denominado Resumo de Projeto (RP). Assim, a passagem de uma fase para outra deve atender a todos os itens determinados para aquele estágio e devem ser registrados no RP. A aprovação de todos RPs é realizada pela diretoria da empresa, que libera os recursos necessários para a execução da fase seguinte. A reprovação de um RP implica na necessidade de correções das atividades e/ou projeto, ou ainda no próprio cancelamento do projeto.

O projeto é acompanhado de forma sistemática, com datas agendadas pelo piloto e equipe de projeto. O encontro ocorre em reuniões denominadas Reuniões de Equipe de Projeto (REP), sob a coordenação do piloto de projetos. As reuniões são orientadas por uma pauta de atividades a serem executadas e por um cronograma de acompanhamento. A Figura 5 apresenta um exemplo de controle desenvolvido pelo Piloto do Projeto no monitoramento das atividades da equipe de projeto.

\section{Figura 5}

Revista de Administração e Inovação, São Paulo, v. 12, n.3 p. 288-309, jul./set. 2015. 
Cronograma de acompanhamento das reuniões de Resumo de projeto RP

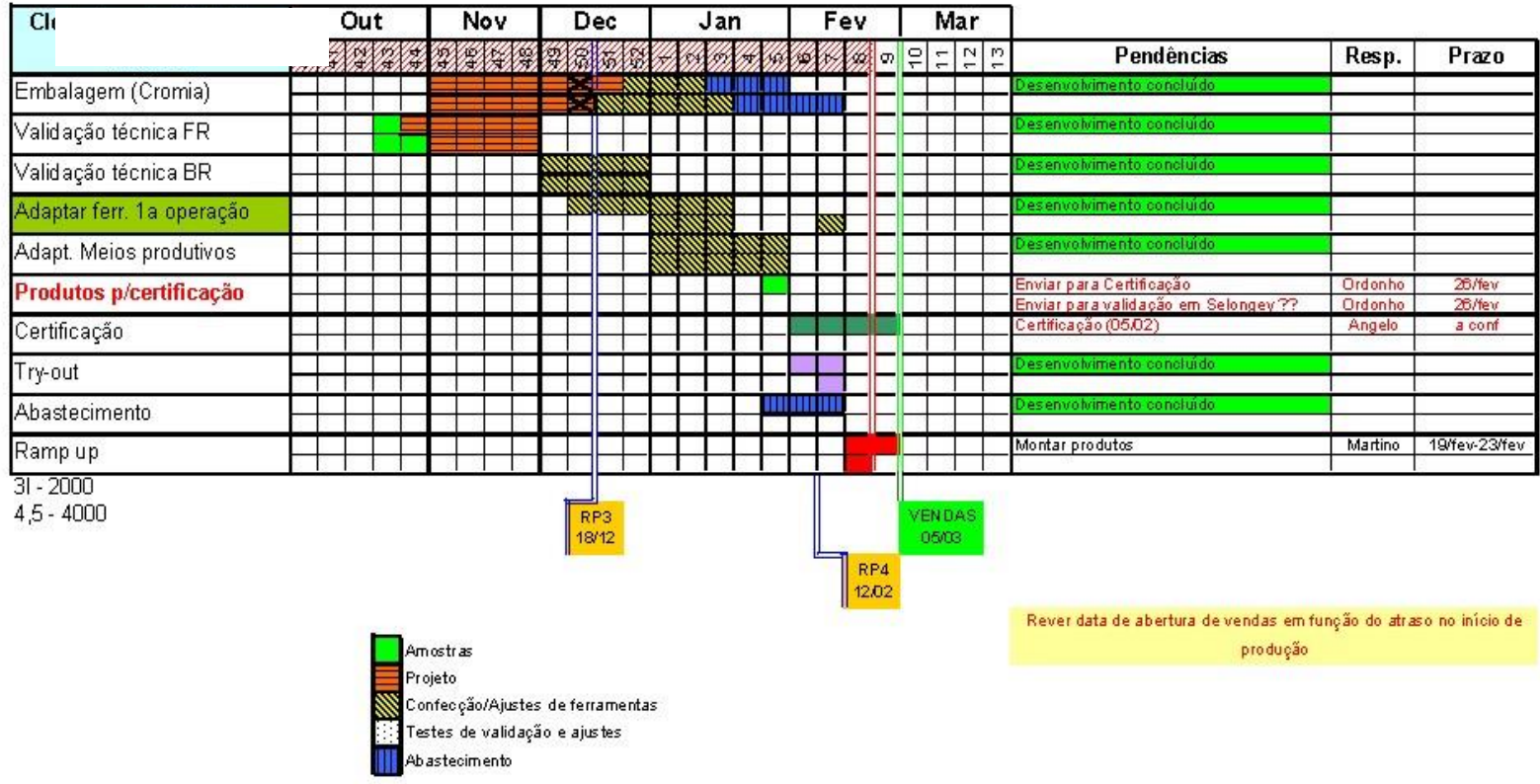

Fonte: dados fornecidos pela EletrodomésticosA.

O RP se constitui em um relatório que apresenta todos os itens necessários para avaliação e aprovação da respectiva fase do projeto. A aprovação do RP é de responsabilidade da diretoria da empresa. Dessa forma, o Piloto do Projeto tem a atribuição de preparar toda a documentação necessária e agendar a reunião. Ao final da reunião, o Piloto de Projeto deve consolidar toda a documentação envolvida e transformar o material em documento oficial da organização, com o arquivamento em biblioteca especifica que possibilita pesquisas futuras. Vale destacar, a utilização de um check-list para assegurar a análise de todos os procedimentos necessários para a realização das reuniões de RP. A Figura 6 apresenta um exemplo de check-list utilizado pela EletrodomésticosA.

\section{Figura 6}

Revista de Administração e Inovação, São Paulo, v. 12, n.3 p. 288-309, jul./set. 2015. 
Check-list utilizado na reunião de RP.
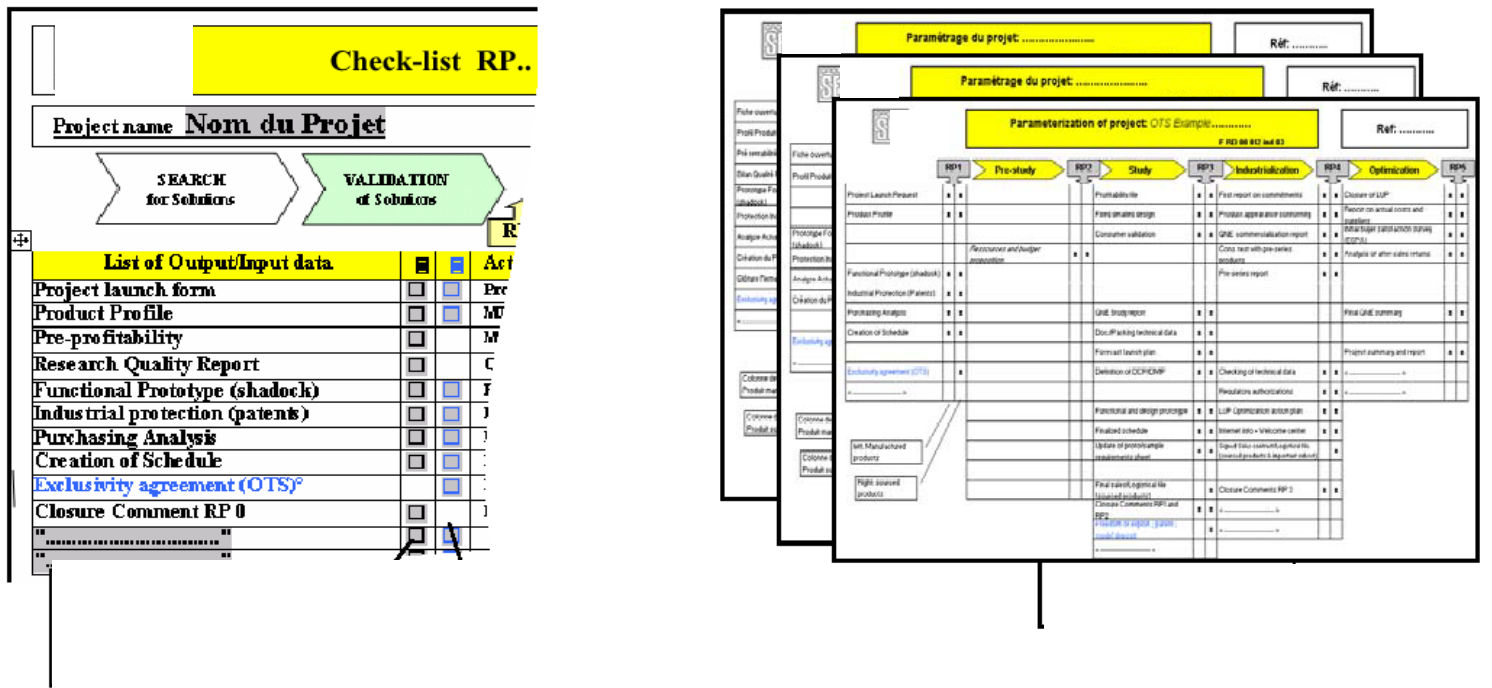

Fonte: dados fornecidos pela EletrodomésticosA.

A Figura 7 mostra o gráfico de desempenho de um produto após o inicio das vendas. O eixo da abscissa indica a quantidade de meses após o lançamento do produto, o eixo das ordenadas indica o índice de retorno de produtos à Assistência Técnica. A Linha de 1,8\% indica a taxa máxima de retorno tolerada nesta fase do projeto, enquanto a linha curva indica o desempenho observado no campo.

Figura 7

Taxa de aparelhos novos que retornam a Assistência Técnica.

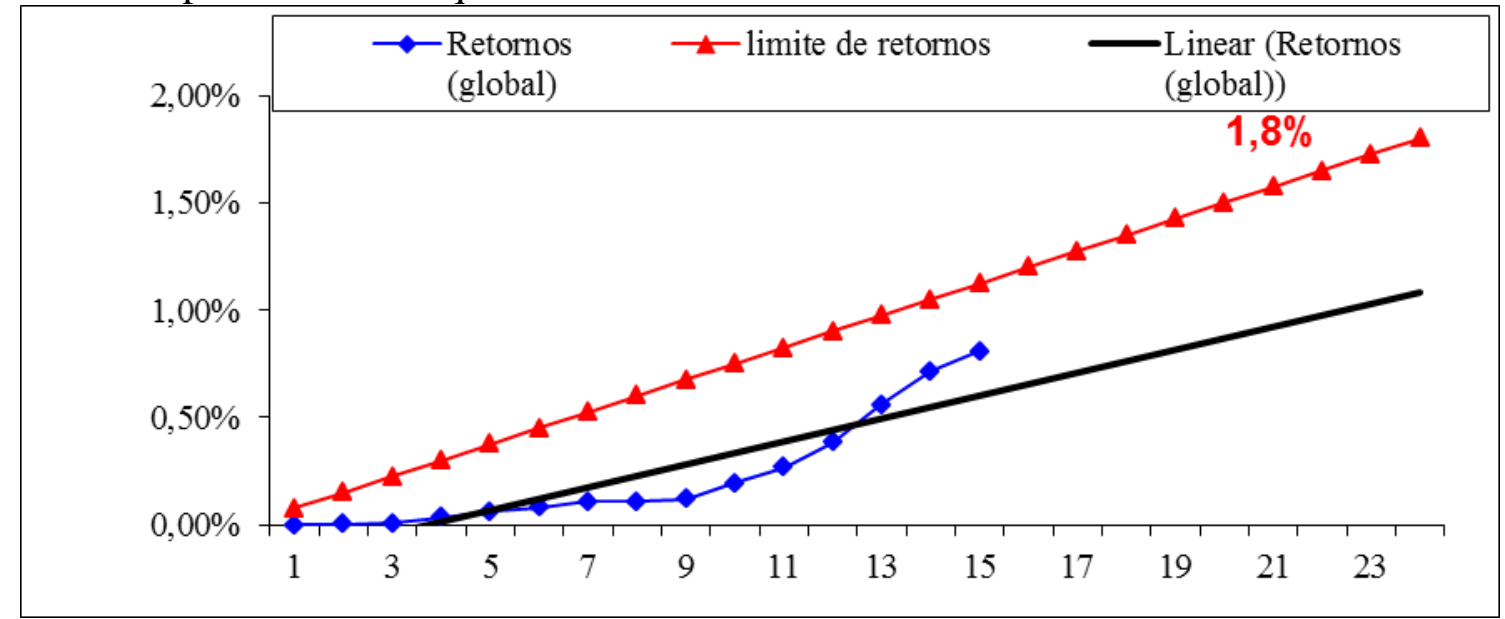

Fonte: dados fornecidos pela EletrodomésticosA.

$\mathrm{Na}$ seção seguinte os dados levantados são analisados frente ao referencial teórico desenvolvido. 


\section{ANÁLISE DOS DADOS}

Os dados observados na EletrodomésticosA mostram que a empresa possui um processo definido e sistematizado de acompanhamento de produtos novos, com protocolos muito bem definidos para suportar as atividades requeridas. Nesse sentido, vale a pena rever o proposto por Shenhar e Dvir (2007), para quem o projeto se destina a disciplinar a análise de benefícios e riscos envolvidos na execução, bem como estabelecer regras e comportamentos para projetos que possuam similaridades. Ademais, a empresa incrementa o alinhamento com o ambiente externo e a integração das diferentes áreas técnicas, necessária para atender à complexidade tecnológica.

O grande desafio na gestão dos processos de inovação é a criação de uma estrutura organizacional que atenda com eficiência a integração dos diferentes agentes que compõem a empresa. Como assinalam Rabechini Junior et al. (2011), nem sempre a estrutura organizacional é adequada para o gerenciamento dos projetos que envolvem o desenvolvimento das inovações, de tal forma que é de substancial importância identificar formas de gestão que favoreçam o envolvimento das pessoas no desenvolvimento das inovações, não se atendo somente ao atendimento das atividades de rotina. Nessa direção vários autores acentuam a inadequação da estrutura funcional, dado o seu caráter mecanicista, apontando para formas mais orgânicas, como a matricial e a organização por projeto.

O caso da Eletrodomésticos A é bastante ilustrativo. O gerenciamento do produto busca atender às atividades de acompanhamento do projeto e comporta quatro fases distintas. Para a condução destas fases se estabelece um Piloto do Projeto e uma equipe multidisciplinar de projeto com atribuições específicas. Fica bem evidente que a Equipe de Projetos é definida a partir da diversidade de competências dos membros da organização (conhecimentos e "know-how"). Nesse sentido, reforça o destaque que Kessler, Bierly e Gopalakrishnan (2000) dão à importância do conhecimento gerado nas atividades da equipe de desenvolvimento.

O principal objetivo declarado do processo de desenvolvimento (e da Equipe de Projeto) manifestado pela EletrodomésticosA é o de respeitar os compromissos assumidos em termos de qualidade, custos e prazos dos lançamentos dos novos produtos. Tal posicionamento é o mesmo do destacado por Raz, Shenhar e Dvir (2002) e Ibbs e Kwak, (2000), que posicionam as variáveis prazo e custo como principais elementos de controle de desempenho das equipes de projeto.

A Figura 4 mostra a equipe de projeto da EletrodomésticosA, constituída em uma estrutura matricial na qual os componentes, além de exercerem as atividades rotineiras, possuem o compromisso de participar do desenvolvimento de projetos, implicando em multiplicidade de linhas de comando. A estrutura empregada pela EletrodomésticosA se aproxima da abordagem de Rabechini Junior et al.

Revista de Administração e Inovação, São Paulo, v. 12, n.3 p. 288-309, jul./set. 2015. 
(2011), que favorece a integração dos elementos (participantes) na busca de soluções conforme destacado por Patah e Carvalho (2002). Nesse sentido, a estrutura organizacional utilizada para o desenvolvimento de projetos da EletrodomésticosA se caracteriza como "matricial pilotada" por um gerente de projetos, que possui autoridade sobre os demais componentes da equipe de projetos de inovação. Esta estrutura tem aderência à proposta por Meredith e Mantel Junior (2000) e Kerzner (2001).

A equipe de projetos da EletrodomésticosA se configura como um "escritório de projetos" dentro da organização com a finalidade especifica de administrar todas as etapas envolvidas no desenvolvimento do novo produto e realizar a interface com a alta administração. Essa configuração organizacional se assemelha às boas práticas do denominado Bodies of Knowledge-Books, destacado por Bernstein (2000), Kendall e Rollins (2003) e Williams (2005). Vale assinalar, que esta configuração reflete o estágio avançado de desenvolvimento da EletrodomésticosA, no âmbito da gestão de projetos de inovação, conforme enfatizado por Rodrigues, Rabechini Júnior e Csillag (2006).

Com relação aos instrumentos de controle, a Figura 4 expressa o processo de desenvolvimento de produto utilizado pela EletrodomésticosA. Comparado com o modelo Stage Gate ${ }^{\mathrm{TM}}$ (Cooper, 1995), é possível observar que a gestão do projeto de inovação segue etapas estabelecidas e com finalidades especificas. A empresa realiza a finalização de cada uma das etapas por intermédio do Resumo de Projeto (RP) que, por sua vez, se constitui de uma reunião onde se observa a aderência dos resultados obtidos até o momento com as metas estabelecidas, e pode ser observado na Figura 6. Essa configuração se assemelha à apresentada por Diegel (2002), na qual as atividades são desenvolvidas de forma organizada. Vale destacar ainda que a reunião também possibilita à administração verificar como está o andamento do projeto como um todo, realizando assim o feedback conforme indicado por Cooper (1995).

A preocupação com o controle dos projetos por parte da alta administração é uma das características centrais do modelo de gestão da inovação, ao lado da estrutura matricial. O acompanhamento do projeto está dividido em duas etapas: a primeira destinada a validar tecnologicamente as inovações a serem implantadas no produto, enquanto a segunda destina-se efetivamente à gestão do projeto. Tal configuração aproxima o modelo de gestão de projetos de inovação da EletrodomésticosA do apresentado por Caetano, Kurumoto e Amaral (2012), que também dividem em dois processos a implantação de um novo produto. Destaca-se ainda que o modelo da EletrodomesticosA segue a abordagem de Shenhar e Dvir (2007) que aporta o projeto em Estrutura Analítica de Projeto - EAP, condicionando-o a um controle do projeto, destinado a garantir a sua realização dentro do prazo, do orçamento, e das especificações. O modelo da EletrodomésticosA 
incorpora inclusive os processos de feedback entre o operacional e a alta administração, apontados como necessários pelos autores.

Destaca-se neste contexto, a participação da alta administração no desenvolvimento do processo. As reuniões de Resumo de Projeto (RP) e os respectivos check-list utilizados possibilitam à alta administração identificar o andamento do projeto. Mediante as informações, a alta administração possui condições de definir a continuidade ou não do projeto, a necessidade de ajustes e principalmente chancelar a disponibilidade de recursos para a continuidade do projeto. As reuniões de Projeto se constituem em eventos importantes para a alta administração, tanto pelo envolvimento direto com o andamento do projeto, quanto por possibilitar a identificação das ameaças para o atendimento das propostas inicialmente estabelecidas.

Finalmente, a EletrodométicosA efetua o monitoramento do desempenho do projeto de inovação. Conforme revela a Figura 7, o acompanhamento de desempenho do produto ocorre após o inicio do processo de comercialização. Esta ação retrata que a equipe de projeto está orientada para o mercado, fato este que reforça a integração e a confiança de seus participantes, conforme aponta Sbragia e Lima (2013).

\section{CONCLUSÃO}

O modelo de gestão de projetos utilizado pela empresa EletrodomésticosA apresenta aderência às propostas dos autores da área e similaridades com os modelos teóricos apresentados na literatura. Caracteriza-se por possuir uma Equipe de Projetos configurada a partir de uma estrutura matricial, com um Piloto de Projetos que possui a atribuição de gerir tanto o projeto quanto a equipe em si.

O processo de gestão dos projetos é dividido em etapas distintas com atribuições especificas e que demandam a necessidade de protocolos de encerramento. $\mathrm{O}$ encerramento de uma fase é que possibilita o inicio da fase seguinte. Esta transição de fases é marcada por uma reunião, em que a equipe de projeto posiciona a alta administração sobre o desempenho alcançado até o momento, com destaque para as informações referentes a custos e prazo.

Na investigação desenvolvida, observou-se a importância de atuação da Equipe de Projeto, do Piloto de Projetos e da alta administração. O caráter multidisciplinar da equipe de gestão do projeto é marcante, revelando a necessidade de integrar a multiplicidade de conhecimentos disponíveis no interior da organização. O Piloto do Projeto é figura central, uma vez que atua como agente integrador da multidisciplinaridade e faz a ponte da equipe com a alta administração. Esta, por sua vez,

Revista de Administração e Inovação, São Paulo, v. 12, n.3 p. 288-309, jul./set. 2015. 
Gestão de projetos de inovação: o caso de uma empresa líder do setor de eletrodomésticos

desempenha um papel decisivo na gestão do projeto, por ser a responsável pela sua continuidade, bem como pelos recursos a serem alocados.

Nesse sentido, surge o interesse em pesquisas futuras voltadas à identificação do papel do Piloto do Projeto e da alta administração. Em particular, caberia pesquisa específica destinada a evidenciar o papel da alta administração frente a eventuais problemas como atrasos de prazos e variações de custo. Tal investigação potencializaria identificar se as ações realizadas pela alta administração exercem influencia positiva ou negativa sobre a equipe e sobre o projeto.

A despeito das limitações da pesquisa, por se tratar de um caso único, não possibilitando a comparação com outras empresas a fim de identificar semelhanças e diferenças existentes, o esforço da investigação permitiu identificar configurações da gestão de projetos de inovação utilizados em uma empresa inovadora, abrindo espaço para futuras pesquisas, em particular a sugerida anteriormente.

\section{REFERENCIAS}

Bremser, W. G., \& Barsky, N. P. (2004). Utilizing the balanced scorecard for R\&D performance measurement. $R \& D$ Management, 34(3), 229-238.

Bernstein, S. (2000). Project offices in practice. Project Management Journal, 30(4), 4-7.

Caetano, M., Kurumoto, J. S., \& Amaral, D. C. (2012). Estratégia de Integração Entre Tecnologia e Produto: identificação de atividades críticas no processo de inovação. Revista de Administração $e$ Inovação, 9(2), 124-148, abr./jun.

Chaos Report. (1995). The Standish Group Report. Recuperado em 12 setembro, 2012, de http://www.scs.carleton.ca/ beau/PM/ Standish-Report.html.

Cooper, R. G. (1995). How to launch a new product successfully. Management Accounting Magazine, 69(8), 20-23.

De Negri, J. A., \& Salerno, M. S. (Org.). (2005). Inovações, padrões tecnológicos e desempenho das firmas industriais brasileiras. Brasília: IPEA

Diegel, O. (2002, fevereiro). Designing breakdown structures: an extension to the work breakdown structure to manage innovation in new product development projects. Proceedings of the Project Management Institute Annual Seminars \& Symposium, San Antonio, Texas, USA.

Gil, A. C. (2010). Como elaborar projetos de pesquisa (5ª ed.). São Paulo: Atlas.

Ibbs, C. W., \& Kwak, Y. H. (2000). Assessing Project Management Maturity. Project Management Journal, 31(1), 32-43. 
Joshi, A. W., \& Sharma, S. (2004). Customer knowledge development: antecedents and impact on new product performance. Journal of Marketing, 68(4), 47-59. Retrieved may 12, 2013, from http://dx.doi.org/10.1509/ jmkg.68.4.47.42722

Kendall, G. I., \& Rollins, S. C. (2003). Advanced Project Portfolio Management and the PMO. Florida: J. Ross Publishing.

Kerzner, H. (2001). Applied project management best practices on implementation. New York: John Wiley \& Sons.

Kessler, E. H., Bierly, P. E., \& Gopalakrishnan, S. (2000). Internal vs. external learning in new product development: effects on speed, costs and competitive advantage. $R \& D$ Management, 30(3), 213-223.

Marques Junior, L. J. (2000). Uma contribuição para melhoria do planejamento de empreendimentos de construção em organizações públicas. (Dissertação de Mestrado). Escola Politécnica da Universidade de São Paulo, São Paulo, SP, Brasil.

Meredith, J. R., \& Mantel Junior, S. J. (2000). Project Management: a managerial approach. New York: John Wiley \& Sons.

Organization for Economic Co-Operation and Development [OECD]. (2005). Promoting innovation in services. Paris: OECD.

Patah, L., \& Carvalho, M. M. (2002). Estruturas de gerenciamento de projetos e competências em equipes de Projetos. Anais do Encontro Nacional de Engenharia de Produção, Curitiba, PR, Brasil, 22.

Rabechini Junior, R., Carvalho M. M., Rodrigues, I., \& Sbragia, R. (2011). A organização da atividade de gerenciamento de projetos: os nexos com competências e estrutura. Revista Gestão \& Produção, São Carlos, 18(2), 409-424.

Raz, T., Shenhar, A., \& Dvir, D. (2002). Risk management, project success, and technological uncertainty. R\&D Management, 32(2), 101-109. Fromhttp:// dx.doi.org/10.1111/1467-9310.00243

Rodrigues, I., Rabechini Júnior, R., \& Csillag, J. M. (2006). Os Escritórios de Projetos como Indutores de Maturidade em Gestão de Projetos. Revista de Administração (FEA-USP), 41, 273-287.

Sbragia, R., \& Lima, M. O. (2013, jul./set.). Orientação para mercado e interface funcional: evidências em projetos de desenvolvimento de novos produtos. Revista de Administração e Inovação, São Paulo, 10(3), 184-207. DOI: 10.5773/rai.v10i3.937.

Schumpeter, J. (1939). Business Cycles: a theoretical, historical and statistical analysis of the capitalist process. Philadelphia: Porcupine.

Schumpeter, J. (1982). Teoria do desenvolvimento econômico. São Paulo: Abril Cultural.

Shenhar, A. J., \& Dvir, D. (2007). Reinventing project management: the diamond approach to successful growth and innovation. Boston: Harvard Business School Press.

Williams, T. (2005). Assessing and moving on from the dominant Project management discourse in the light of Project overruns. IEEE Transactions on Engineering Management, 52(4), 497-508. 
Yin, R. K. (2010). Estudo de caso: planejamento e métodos (4a. ed.). Porto Alegre: Bookman.

\title{
PROJECT MANAGEMENT OF INNOVATION: THE CASE OF A LEADING INDUSTRY OF
}

\section{APPLIANCES}

\begin{abstract}
The study aims to identify management settings innovation projects used in organizations. Developed a qualitative study using the technique of case study. The conducted case study covers a leader in the home appliance industry, located among the ten companies that register patents in Brazil. The observed data show that the company has a defined and systematic process of monitoring of new products, with well defined protocols to support the required activities in order to discipline the analysis of benefits and risks involved in the execution, and establish rules and behaviors for projects have similarities. In addition, the company enhances the alignment with the external environment, enabling the integration of different technical areas, to meet the technological complexity. The results indicate that the company adopts an innovation management model supported by a Project Team set from a matrix structure, with a Pilot Project. The Pilot Project is positioned as the central process agent, to act as an integrator of multidisciplinary agent and make the bridge team with senior management. The configuration management process is presented divided into different stages with specific tasks that require control procedures, embodied in "closing protocols." The approval of the project is carried out by senior management in each stage, in specific meetings that analyze, costs, compliance with deadlines and the technological development of current innovations.
\end{abstract}

Key-words: Project office; Project management; Team projects; Pilot projects.

Data do recebimento do artigo: 28/05/2014

Data do aceite de publicação: 13/03/2015

Revista de Administração e Inovação, São Paulo, v. 12, n.3 p. 288-309, jul./set. 2015. 